\title{
Single nucleotide polymorphisms in CETP, SLC46A1, SLC19A1, CD36, BCMO1, APOA5, and ABCA1 are significant predictors of plasma $\mathrm{HDL}$ in healthy adults
}

\author{
Andrew J Clifford ${ }^{1 *}$, Gonzalo Rincon², Janel E Owens ${ }^{3}$, Juan F Medrano², Alanna J Moshfegh ${ }^{4}$, David J Baer ${ }^{5}$
} and Janet A Novotny ${ }^{5}$

\begin{abstract}
Background: In a marker-trait association study we estimated the statistical significance of 65 single nucleotide polymorphisms (SNP) in 23 candidate genes on HDL levels of two independent Caucasian populations. Each population consisted of men and women and their HDL levels were adjusted for gender and body weight. We used a linear regression model. Selected genes corresponded to folate metabolism, vitamins B-12, A, and E, and cholesterol pathways or lipid metabolism.
\end{abstract}

Methods: Extracted DNA from both the Sacramento and Beltsville populations was analyzed using an allele discrimination assay with a MALDI-TOF mass spectrometry platform. The adjusted phenotype, y, was HDL levels adjusted for gender and body weight only statistical analyses were performed using the genotype association and regression modules from the SNP Variation Suite $v 7$.

Results: Statistically significant SNP (where $P$ values were adjusted for false discovery rate) included: CETP (rs7499892 and rs5882); SLC46A1 (rs37514694; rs739439); SLC19A1 (rs3788199); CD36 (rs3211956); BCMO1 (rs6564851), APOA5 (rs662799), and ABCA1 (rs4149267). Many prior association trends of the SNP with HDL were replicated in our cross-validation study. Significantly, the association of SNP in folate transporters (SLC46A1 rs37514694 and rs739439; SLC19A1 rs3788199) with HDL was identified in our study.

Conclusions: Given recent literature on the role of niacin in the biogenesis of $H D L$, focus on status and metabolism of B-vitamins and metabolites of eccentric cleavage of $\beta$-carotene with lipid metabolism is exciting for future study.

Keywords: Single nucleotide polymorphism, HDL, Folate transporter, Cholesterol

\section{Background}

Understanding the effects of genetic, environmental, and especially of lipid levels on health status, is of wide and significant interest [1]. The relationships between persistent environmental pollutants and micronutrient levels are not well understood; though such speculation includes the role of peroxisome proliferator-activated receptor (PPAR), transcription factors related to lipid homeostasis, or changes in

\footnotetext{
* Correspondence: ajclifford@ucdavis.edu

'Department of Nutrition, University of California, One Shields Avenue, Davis, CA 95616, USA

Full list of author information is available at the end of the article
}

DNA methylation patterns [1]. In our recent work [2], we investigated 65 single nucleotide polymorphisms (SNP) in 23 candidate genes involved in folate metabolism (8 genes), vitamins B-12, A, and E metabolism (5 genes), and cholesterol pathways or lipid metabolism (10 genes) in a homocysteine/red blood cell folate marker trait association study. Interestingly, a few SNP associated with diabetes mellitus (DM), cardiovascular disease (CVD) and maintenance of the cholesterol pathway or lipid metabolism were identified: serine palmitoyltransferase (SPTLC1 rs117 90991), cholesteryl ester transfer protein (CETP rs5882) and scavenger receptor class $\mathrm{B}$ type 1 (SCARB1 rs838892).

\section{Biomed Central}


SNP associated with transfer of antioxidant vitamins, including rs2118981 in the cellular retinol binding protein II gene (CRBP2), which is important for vitamin A and retinoid transfer, and rs838892 SCARB1 (for tocopherols and tocotrienols), were also statistically significant predictors in the final model. Significantly, SNP in betaine-homocysteine methyltransferase (BHMT rs3733890) and methylene tetrahydrofolate reductase (MTHFR rs1801131), both of which are involved in one-carbon metabolism, were also included in the final model that was previously described [2].

Given the establishment of these associations in our previous work [2], further investigation of the relation of folate, homocysteine (Hcy), and changes in plasma lipid profiles was of significant research interest. High levels of Hcy and changes in plasma lipids are independent risk factors for development of CVD, and there may be a connection between Hcy metabolism and lipid metabolism [3]. Low levels of dietary folate, an important cofactor in the metabolism of Hcy, led to increased levels of serum and liver cholesterol in wild-type mice [4]. As well, cholesterol metabolism may contribute to beneficial effects of dietary folate supplementation [4]. Possible connections, not yet fully supported by experimental data, between folate levels and cholesterol biosynthesis include endoplasmic reticulum stress, which activates cholesterol biosynthesis genes, or through metabolic processes involving choline. Choline provides methyl groups for Hcy metabolism and is a precursor for choline phospholipids, which are required for lipoprotein secretion [4]. Additionally, serum lipid levels are risk factors for a number of adverse health outcomes, including coronary heart disease (CHD), atherosclerosis, type 2 DM, stroke, and metabolic syndrome [1]. Lipid levels of interest include triglycerides, low-density lipoprotein (LDL), and high-density lipoprotein (HDL), especially as recent work has indicated that HDL may not always be protective against atherosclerosis [5,6]. Particularly, the functionality and quality of HDL [7] in response to vascular inflammation and oxidative stress [5] is an interesting area of further study. HDL is required in the reverse cholesterol transport (RCT) mechanism where excess cholesterol is transferred from peripheral cells to the liver for intestinal excretion [8]. Additionally, HDL has anti-inflammatory and antioxidant effects and improves endothelial function [8].

In this study we selected 65 SNP in 23 candidate genes to perform a marker trait association study with plasma HDL adjusted for gender and body weight in Caucasian male and female study participants from two independent populations (Sacramento, California, and Beltsville, Maryland). Selected SNP corresponded to 8 genes associated with folate metabolism, 5 genes associated with vitamin $\mathrm{B}-12$, vitamin $\mathrm{A}$ and vitamin $\mathrm{E}$ metabolism, and 10 genes associated with cholesterol pathways or lipid metabolism. The overall objective of this study was to determine if any of these SNP in the 23 candidate genes had a statistically significant association with HDL.

\section{Results}

\section{Significant SNP predictors}

Tables 1 and 2 include significant SNP predictors on HDL concentrations $(\mathrm{mg} / \mathrm{dL})$ that were validated in both the Sacramento and Beltsville populations, respectively. Each table lists the gene with corresponding statistically significant SNP predictor (with associated $P$-value) and the square of the correlation coefficient $\left(R^{2}\right)$ indicating the proportion of response variation explained by the regressors in the model. The ASE in Tables 1 and 2 represents the allele substitution effect, which is the slope derived from the regression, and where a positive ASE indicated a positive association with the adjusted HDL and conversely, a negative ASE indicated a negative association. The false discovery rate (FDR) was corrected for any chance findings. The minor allele frequency (MAF) is the frequency at which the less common allele occurs in the population indicating also the frequency of the allele causing the effect.

Statistically significant SNP predictors in the Sacramento and Beltsville populations were similar between both groups though there were some differences in the directionality and magnitude of the association between SNP predictor and HDL. SNP of genes that were statistically significant included: 1) cholesteryl ester transfer protein (CETP; rs7499892 and rs5882); 2) proton-coupled folate transporter (SLC46A1; rs35714695 and rs739439); 3) reduced folate carrier (SLC19A1; rs3788199); 4) thrombospondin receptor (CD36; rs3211956); 5) beta-carotene monooxygenase 1 (BCMO1; rs6564851); 6) apolipoproteinA-V (APOA5; rs662799); and 7) ATP-binding cassette transporter member 1 (ABCA1; rs4149267).

The two SNP included in this study for CETP (rs7499892 and rs5882) with MAF of $\sim 0.16$ and MAF of $\sim 0.04$ for the rare allele, respectively, were statistically

\section{Table 1 Sacramento population}

\begin{tabular}{lllllll}
\hline Gene & SNP predictor & $\boldsymbol{P}$-value & $\mathbf{R}^{\mathbf{2}}$ & ASE & FDR & MAF \\
\hline CETP & rs7499892 & 0.000437 & 0.098 & -2.309 & 0.0015 & 0.15 \\
CETP & rs5882 & $2.16 \mathrm{E}-05$ & 0.205 & -10.250 & 0.0004 & 0.05 \\
SLC46A1 & rs35714695 & $2.62 \mathrm{E}-06$ & 0.160 & -6.644 & 0.0002 & 0.15 \\
SLC46A1 & rs739439 & $6.03 \mathrm{E}-06$ & 0.207 & -6.713 & 0.0002 & 0.17 \\
SLC19A1 & rs3788199 & 0.000209 & 0.226 & 2.828 & 0.0012 & 0.45 \\
CD36 & rs3211956 & $9.39 \mathrm{E}-08$ & 0.183 & 4.372 & $1.14 \mathrm{E}-06$ & 0.07 \\
BCMO1 & rs6564851 & 0.000456 & 0.114 & 0.586 & 0.0014 & 0.49 \\
APOA5 & rs662799 & 0.000491 & 0.148 & -4.523 & 0.0013 & 0.05 \\
ABCA1 & rs4149267 & $4.59 \mathrm{E}-08$ & 0.195 & -3.236 & $9.76 \mathrm{E}-07$ & 0.37 \\
\hline
\end{tabular}

Significant SNP predictors on HDL concentrations $(\mathrm{mg} / \mathrm{dL})$ in the Sacramento population $(n=249)$. 
Table 2 Beltsville population

\begin{tabular}{lllllll}
\hline Gene & SNP predictor & $\boldsymbol{P}$-Value & $\mathbf{R}^{\mathbf{2}}$ & ASE & FDR & MAF \\
\hline CETP & rs7499892 & $3.10 \mathrm{E}-05$ & 0.097 & -2.088 & 0.0002 & 0.16 \\
CETP & rs5882 & $9.57 \mathrm{E}-05$ & 0.086 & -2.145 & 0.0002 & 0.04 \\
SLC46A1 & rs35714695 & $6.21 \mathrm{E}-05$ & 0.091 & 1.606 & 0.0002 & 0.17 \\
SLC46A1 & rs739439 & $8.33 \mathrm{E}-05$ & 0.091 & 1.323 & 0.0002 & 0.18 \\
SLC19A1 & rs3788199 & 0.001037 & 0.085 & 1.796 & 0.0100 & 0.41 \\
CD36 & rs3211956 & $7.93 \mathrm{E}-05$ & 0.089 & 1.774 & 0.0002 & 0.07 \\
BCMO1 & rs6564851 & $7.90 \mathrm{E}-05$ & 0.088 & 1.015 & 0.0002 & 0.49 \\
APOA5 & rs662799 & $6.72 \mathrm{E}-05$ & 0.091 & -0.471 & 0.0002 & 0.06 \\
ABCA1 & rs4149267 & 0.00143 & 0.071 & -2.070 & 0.0078 & 0.38 \\
\hline
\end{tabular}

Significant SNP predictors on HDL concentrations $(\mathrm{mg} / \mathrm{dL})$ in the Beltsville population $(n=532)$

significantly negatively associated with HDL-C in both the Sacramento and Beltsville populations (Tables 1 and 2) as indicated by the ASE (slope of the regression). It was determined that the rs3788199 SNP in SLC19A1 was positively correlated with HDL levels (ASE $=2.828$ for the Sacramento population, Table 1; ASE $=1.796$ for the Beltsville population, Table 2). The SNP rs35714695 and rs739439 of SLC46A1 were both negatively associated with HDL levels in the Sacramento population though the Beltsville population had a positive association with HDL levels, which indicates that the allele effects are opposite. The directionality of this association difference is one area of future study. In the present study, a very large positive association between HDL levels and the presence of rs3211956 of CD36 was also identified for both study populations (Table 1 and Table 2). In the Sacramento population, the ASE was 4.372, with similar positive association (but not as large) found in the Beltsville population (ASE $=1.774)$. The results of the present study support a past finding: in both populations (Sacramento and Beltsville), a positive association, as indicated by the positive ASE values (Table 1, ASE $=0.586$ and Table 2, ASE $=$ 1.015), was established for the rs6564851 SNP of $B C M O 1$ and plasma HDL levels. For APOA5, the rs662799 SNP was statistically significantly negatively associated with HDL. The ASE was -4.523 for the Sacramento population (Table 1 ) and -0.471 for the Beltsville population (Table 2), indicating that there was a negative association of the presence of this SNP with measured HDL concentrations. Finally, the SNP rs4149267 of $A B C A 1$ was associated with HDL-C in both Caucasian populations with similar ASE of -3.236 in the Sacramento population (Table 1) and -2.070 in the Beltsville population (Table 2).

\section{Discussion \\ CETP}

CETP encodes cholesteryl ester transfer protein, which exchanges the triglycerides from VLDL and LDL particles for cholesterol esters from HDL. CETP also selectively enhances liver HDL cholesterol ester uptake [9]. Inhibiting CETP with various pharmacologic agents (torcetrapib, dalcetrapib, anacetrapib, evacetrapib) has been an attractive means to minimize risk for adverse cardiovascular events because of a potential rise in HDL-C and fall in LDL-C $[8,10]$. Understanding the molecular basis for cholesteryl ester transport by CETP is of research interest to support the development of other CETP inhibitors [11]. In a previous genome wide association study (GWAS), the SNP rs708272 (or TaqIB SNP) of CETP had the strongest association with HDL-C of all 948 SNPs genotyped in 122 genes though this SNP was not included in our study. As well, this SNP had a strong association with apolipoproteinA-1 (apoA1) [12]. In a population of Chinese Bama Zhuang individuals, the rs708272 SNP was associated with higher HDL-C levels, but the outcome of this SNP on longevity was less clear [13]. A recent meta-analysis of 46 lipid GWAS, six HDL-C loci were identified with at least a second independent association with HDL-C including $L P L, A B C A 1$, APOA1/A4/A5/C3, ZNF664, LIPC, and CETP [14]. Both $A B C A 1$ and $C E T P$ were validated in our study. Tietjen and colleagues showed that rare coding and splicing mutations on CETP were enriched in persons with hyperalphalipoproteinemia and segregated with elevated HDL-C in families [15].

In our prior study, rs5882 of CETP was statistically significantly associated with Hcy normalized by red blood cell folate concentrations [2]. Two of the four SNP included in this study for CETP (rs7499892 and rs5882) were statistically significantly negatively associated with HDL-C in both the Sacramento and Beltsville populations (Tables 1 and 2). The rs5882 SNP has been associated with lower CETP serum concentrations and activity, increased HDL cholesterol levels, and increased lipoprotein sizes, all factors which have been associated with a lower CVD risk [16]. In a recent study in Tunisian population, there was no statistically significant association of the rs5882 SNP with lipoprotein metabolism or atherogenicity [17].

\section{SLC46A1 and SLC19A1}

The proton-coupled folate transporter (PCFT, gene symbol SLC46A1) mediates intestinal folate absorption and folate transport across the choroid plexus. PCFT has an optimal pH transport of $5.0-5.5$ (jejunum and duodenum), but the role of this transporter in other tissues at normal physiological $\mathrm{pH}$ is less clear [18]. Homozygous mutations in SLC46A1 have been associated with a rare disorder, hereditary folate malabsorption [18]. Solute carrier family 19 (folate transporter) member 1 , also known as the reduced folate carrier (RFC; gene symbol SLC19A1), is involved in the regulation of intracellular concentrations of folate. Higher serum folate concentrations have been 
associated with lower levels of LDL-C, lower LDL-C/ $\mathrm{HDL}-\mathrm{C}$ ratio, and higher $\mathrm{HDL}-\mathrm{C}$. These associations were independent of gender or age, though influences of medications, diseases, physical exercise, diet, or BMI were not accounted for in that study. Interestingly, vitamin B12 was not associated with the lipoprotein profile in that reported study [19]. Cholesterol may be important for facilitating the import of folate by clustering membrane-bound folate receptors in the cell membrane [19]. Use of clustering membrane-bound folate receptors was favoured when folate status was low [20]. Folate status is inversely associated with obesity [21], likely due to increased activity of COMT (catechol O-methyltransferase), which uses folate for methyl transfer for metabolism of catechol estrogen produced by adipose tissue. Both obesity [21] and low folate status [19] have been associated with reduced HDL cholesterol levels. However, in a recent study examining folate placental transport in obese women, it was determined that while protein expression of folate receptor- $\alpha$ and RFC were altered (PCFT was unchanged), the activities of the transporters was unaltered in obesity and fetal folate serum concentration were not adversely affected [22]. In the present study, it was determined that the rs3788199 SNP in SLC19A1 was positively correlated with HDL levels (ASE $=2.828$ for the Sacramento population, Table 1; ASE = 1.796 for the Beltsville population, Table 2), which compares well to the earlier retrospective database study previously described [19]. Surprisingly, it was also determined that the SNP rs35714695 and rs739439 of SLC46A1 were both negatively associated with HDL levels in the Sacramento population whereas the Beltsville population had a positive association with HDL levels, which indicates that the allele effects are opposite. To our knowledge, there are no studies providing information on association studies of SNP in SLC46A1 with HDL cholesterol levels. Given the differences in association between the two populations in this study, investigation of SNP in SLC46A1 with HDL is of further research interest.

A 2010 study examined seven SNP variants in genes involved in Hcy metabolism on the interaction with plasma lipid profile. In that study, SLC19A1 (SNP rs1051266) was not found to have a statistically significant association with blood lipid profiles analysed (fasting lipoprotein, total cholesterol, LDL, HDL, and triglyceride levels) [3]. Additional findings from that study implicated SNP in the genes for transcobalamin II (rs1801198) and MTHFR (rs1801133) were associated with blood lipid profiles. The $\mathrm{G}$ allele of rs1801198 was correlated with higher levels of LDL in plasma, lower HDL, higher triglyceride levels, and higher total cholesterol levels [3]. However, in our study, neither rs1801198 (transcobalamin II) nor rs1801133 (MTHFR) were statistically significantly associated with levels of HDL in plasma.

\section{CD36}

CD36 (thrombospondin receptor), or glycoprotein IIIb/ platelet glycoprotein IV is a mediator of platelet adhesion to collagen. The investigation of SNP of CD36 on HDL is not well established, likely because participants in many studies deal with chronic diseases, including DM, CHD, or metabolic syndrome or risk factors for chronic diseases [23-26]. Therefore, CD36 warrants further investigation, with careful statistical control of potentially confounding variables, including environmental factors, dietary factors, and other genotypes. In our study, we enrolled healthy participants as indicated by low use of statins (less than $\sim 7 \%$ for overall study population) and healthy BMI (mean \pm standard deviation for Sacramento was $24.8 \pm 4.2$ and $26.6 \pm 4.6$ for Beltsville). We found that there was a very large positive association between HDL levels and the presence of SNP rs3211956 (Tables 1 and 2). In the Sacramento population the ASE was 4.72 , with similar positive association (but not as large) found in the Beltsville population (ASE=1.774).

\section{BCMO1}

Beta-carotene monooxygenase 1 (BCMO1) catalyzes the first step in the central cleavage and conversion of dietary provitamin carotenoids to vitamin A (retinal) in the small intestine [27,28]. Vitamin A is necessary for immune response, vision, embryonic development, cell differentiation, and membrane and skin protection [27]. The statistically significant SNP identified in the present study, rs6564851, is $7.7 \mathrm{~kb}$ 5' upstream from the BCMO1 gene. This particular SNP has been associated with a $48 \%$ reduced catalytic activity of converting $\beta$-carotene into vitamin $\mathrm{A}$ in female participants in a recent study [29]. Other SNP in BCMO1 have been associated with plasma levels of various carotenoids, including $\beta$ carotene, lutein, $\alpha$-carotene, zeaxanthin, and lycopene [27]; and the G allele of the rs6564851 may explain some of the variance in plasma levels of these provitamin carotenoids. The rs6564851 SNP may be particularly important for individuals at risk for vitamin A deficiency [27] owing to reduced catalytic activity of BCMO1 [29]. Recently, the rs6564851 SNP had the strongest association (when compared to other SNP: rs11645428, rs6420424, and rs8044334) with fasting $\beta$-carotene concentrations in plasma [29]. Higher levels of carotenoids (isomers of $\beta$-carotene, lycopene, and $\beta$-cryptoxanthin) have been associated with higher levels of HDL and LDL in a recent study involving NHANES participants [1]. In a recent review, the important physiological effects of eccentric cleavage products of beta-carotene were discussed. Considering the effects of BCMO1 SNP as well, there could be some very different physiological effects from beta-carotene consumption owing to genetic influences, oxidative stress, and presence of various 
beta-carotene metabolites [28]. Interesting recent work has focused on the retinoid receptor antagonist activity of products resulting from $\beta$-carotene eccentric cleavage, the $\beta$-apocarotenoids [30,31]. The biological activities and effects of these $\beta$-carotene metabolites may be important to consider in evaluating oxidative stress and adverse health outcomes of CVD or cancer [30]. It has been established that there is no association between the BCMO1 SNP rs6564851 and risk of developing type 2 DM [32].

\section{APOA5}

Apolipoprotein A-V is a protein component of HDL. In this study, the rs662799 SNP of APOA5 was identified as being a significant predictor. The ASE was -4.523 for the Sacramento population and -0.471 for the Beltsville population, indicating that there was a negative association of the presence of this SNP with measured HDL concentrations. In a recent study [33], the rs662799 SNP was the only SNP (of thirteen evaluated in the APOA1/ $C 3 / A 4 / A 5$ gene cluster) to be associated with three lipid traits: triglycerides, HDL-C, and LDL-C levels. In this past study, the MAF was statistically significantly associated with familial combined hyperlipidaemia, though the functional effect of this rs662799 SNP may not be well understood [33]. In another recent study, rs662799 was statistically significantly associated with plasma triglycerides in both women and men of the study population and statistically significantly associated with total cholesterol and LDL-C levels in men only. However, the authors concluded that haplotypes for five SNP in the apolipoprotein A1/C3/A5 cluster could explain more serum lipid variation than any one SNP alone, especially for HDL-C [34]. The presence of the rs662799 SNP was statistically significantly associated with lower levels of total cholesterol, triglycerides, and LDL-C in a group of Hei Yi Zhuang Chinese (though this same trend was not observed in Han Chinese), indicating that there may be other gene-gene or gene-environment interactions [35].

\section{ABCA1}

ABCA1 (ATP-binding cassette transporter member 1) plays an important role in cellular cholesterol and phospholipid homeostasis in multiple cell types [36,37] and is involved in RCT [38]. ABCA1 mediated efflux of cholesterol and phospholipids leads to the formation of nascent HDL via apoA1 [39,40]; and mutations that disrupt normal ABCA1 function result in little or no circulating HDL [41]. ABC transporter G1 (ABCG1) promotes cholesterol efflux from macrophages to HDL to form mature HDL particles [40], and hence works in a sequential manner with ABCA1 [42]. All trans-retinoic acid has been shown to increase apoA1/HDL-mediated cholesterol efflux from macrophages by increasing ABCA1 and ABCG1 by regulating promoter activity via liver $\mathrm{X}$ receptor-responsive element mechanism [42]. Wiersma and colleagues [43] also showed that $A B C G 1$ knock-out mice exhibit decreased HDL-C when consuming a high fat diet. In this study, they also demonstrated that ABCG1 mediated cholesterol efflux to HDL [43]. Functional mutations in ABCA1 cause Tangier disease, which is characterized by very low levels of plasma HDL apoA1 [44,45]. In a recent study investigating exome sequencing, functional rare variants in $A B C A 1$ and $L P L$ (gene for lipoprotein lipase) were identified and explained a major portion of the HDL-C variance in the population enrolled in the study [41].

Previous studies have found associations between certain SNP in $A B C A 1$ and HDL concentrations [46-48]. Recent GWAS and meta-analysis studies showed that SNP in $A B C A 1$ were significantly associated with HDL-C $[14,49]$. In our study, the SNP rs4149267 of $A B C A 1$ was associated with HDL-C in both Caucasian populations with similar ASE of -3.236 in the Sacramento population and -2.070 in the Beltsville population.

It would be significant to understand the effects of apolipoprotein E (apoE), which plays an important role in lipoprotein metabolism and atherosclerosis. ApoE has been shown to promote selective uptake of HDL-C owing to increased ABCA1-mediated cholesterol efflux to plasma [50]. This present work identifies significant SNP in $A B C A 1$ and hence this relation with $A B C A 1$ SNP and apoE facilitated HDL-C transport is of future research interest.

\section{Conclusions}

The strength of our study is the cross-validation between two independent populations (one on the West coast, from Sacramento, CA, and one from the East coast, from the Washington, D.C. area) with similar SNP associations identified in both populations. It would be of significant research interest to focus on the relation of $\mathrm{B}$ vitamins on HDL status. In this work, we have identified SNP in two folate transporters (SLC46A1 rs35714695 and rs739439; SLC19A1 rs3788199) having statistically significant ASE in relation to HDL status in both study populations. Cholesterol may be important for facilitating the import of folate across the cell membrane and higher serum folate concentrations have been associated with lower levels of LDL-C and higher levels of HDL-C [19]. Past work by Kitami et al. focused on the importance of the homeostatic role of cholesterol metabolism on folate retention in mouse strains, so there has been an established relationship between cholesterol and folate in the mouse [4]. Recent work by Zhang et al. identified the role of niacin (also known as vitamin B3) on early hepatic HDL formation through transcription of $A B C A 1$. In that study, apoA1 lipidation 
and formation of nascent HDL was mediated and stabilized by niacin, which may prevent premature HDL catabolism [51].

Finally, the identification of the positive association of the BCMO1 SNP rs6564851 with HDL levels was of significance. This SNP has a high MAF in the two independent study populations of this work (Tables 1 and 2). Additionally, the presence of this SNP has been associated with a $48 \%$ reduction in activity of converting $\beta$-carotene into vitamin A through central cleavage, resulting in higher circulating levels of plasma carotenoids [29]. These higher levels of carotenoids may be associated with higher levels of HDL and LDL [1]. The biological effects of the eccentric cleavage products of $\beta$-carotene (the apo- $\beta$-carotenoids), especially on lipid metabolism and oxidative stress, are an exciting area of future study.

\section{Methods}

\section{Study populations}

\section{Sacramento population}

The Institutional Review Board of the University of California, Davis, approved the study, which was conducted according to Good Clinical Practice guidelines and the Declaration of Helsinki, version 1989. Written informed consent was obtained from each participant before enrollment in the study. Women and men ranging in age from 18 to 67 years were recruited by posted, published, and mailed advertisements in the California counties of Sacramento, San Joaquin, Solano, and Yolo from May 2004 through August 2005. Persons were excluded for any history of a serious medical condition, for using medications that could interfere with folate metabolism (including phenytoin, primidone, fosphenytoin, carbamazepine, phenobarbital, ranitidine, trimethoprim, metformin, sulfasalazine, triamterene or methotrexate, beta blockers, and angiotensin inhibitors), for using tobacco, or for heavy consumption of alcohol ( $\geq 3$ drinks per day). Responders to advertisements enrolled in a single clinic visit at the Ragle Human Nutrition Research Center at the University of California, Davis. Before the clinic visit, participants in the study received via US mail a packet containing information about the study, consent forms, instructions to fast for $8-10 \mathrm{~h}$ prior to the clinic visit, and two dietary intake instruments to assess folate intake from the diet and supplements. Folate intake assessed by the Block Dietary Folate Equivalents (DFE) Screener is available through Supporting Information (Additional file 1: Figure S1). At the time of the scheduled visit, participants were interviewed about general medical, personal, and family histories. Gender, age, and BMI (calculated from height and weight measurements) were also recorded. Fasting whole blood samples were then drawn as described below. A \$15 gift certificate to a local supermarket or department store was given to each person at the end of the clinic visit. Two hundred forty-nine individuals were enrolled in the Sacramento population.

\section{Beltsville population}

The Johns Hopkins University Bloomberg School of Public Health Committee on Human Research approved the study procedures and protocol, which was in accord with Good Clinical Practice guidelines and the Declaration of Helsinki, version 1989. The population consisted of 510 adults (257 females, 253 males) aged 30 - 69 years residing in the greater Washington, D.C. area. Participants were recruited to participate in a study of dietary recall between July 2002 and June 2004 [52] and were included in the present study as an adjunct to the previous study. Potential participants were recruited through email, advertisements in local newspapers, and announcements on USDA ARS websites. Participants attended an informational meeting concerning study procedures before completing a health history questionnaire. The questionnaire covered general medical, personal, and family histories. Folate intake assessed by the Block Dietary Folate Equivalents (DFE) Screener is available through Supporting Information (Additional file 1: Figure S1). A medical screening evaluation included measurement of height, weight, blood pressure, and laboratory analysis of fasting blood and urine. Age, BMI (calculated from height and weight measurements) and gender were also recorded. The medical history and laboratory results were reviewed by study investigators and a cooperating physician to confirm good health of the participants and that there was no evidence of underlying disease, untreated thyroid disorders, gastrointestinal disease, malabsorption syndromes, history of eating disorders, cancer, or DM. All participants were weight stable, were not actively pursuing a weight-loss regimen, were not taking medications known to affect food intake or appetite, and were not taking diuretics or other medications that may affect water balance. Pregnant and lactating women were excluded from the study. Participants were compensated according to the requirements of the main study [52].

\section{Blood analysis and genotyping Sacramento population}

Fasting whole blood was collected in triplicate. It was collected 1) into spray-dried $\mathrm{K}_{2}$ EDTA tubes for assessment of complete blood count, red blood cell (RBC) folate, plasma vitamin $\mathrm{B} 6$, and plasma Hcy; 2) into serum separator tubes for the assessment of serum vitamin B12, serum folate, and lipid panel; and 3) into $8.5-\mathrm{mL}$ whole blood DNA tubes for the assessment of genomic DNA. The preparation and analysis of the collected 
Table 3 SNP included in analyses

\begin{tabular}{|c|c|c|c|c|}
\hline Name & Gene, function & Chromosome & dbSNP identifier & $\mathrm{n}$ \\
\hline Apolipoprotein A1 & $\begin{array}{l}\text { APOA1, protein component of } \mathrm{HDL} \text {, promotes } \\
\text { cholesterol efflux from tissues to liver }\end{array}$ & 11 & rs2727784 & 1 \\
\hline Apolipoprotein A5 & $\begin{array}{l}\text { APOA5, protein component of } \mathrm{HDL} \text {, regulates } \\
\text { plasma triglycerides }\end{array}$ & 11 & $\begin{array}{l}\text { rs3135506, rs662799, } \\
\text { rs12272004 }\end{array}$ & 3 \\
\hline $\begin{array}{l}\text { ATP-binding cassette, subfamily A, } \\
\text { member } 1\end{array}$ & $\begin{array}{l}\text { ABCA1, transport AAs, sugars, vitamins, cholesterol, } \\
\text { pt-choline to lipid acceptor apoA1 }\end{array}$ & 9 & $\begin{array}{l}\text { rs2230806, rs2230808, } \\
\text { rs4149267, rs4149327 }\end{array}$ & 4 \\
\hline$\beta$-Carotene 15,15'-monooxygenase 1 & $B C M O 1$, cleave $\beta$-carotene & 16 & $\begin{array}{l}\text { rs12934922, rs6564851, } \\
\text { rs7501331 }\end{array}$ & 3 \\
\hline$\beta$-Carotene oxygenase 2 & $\mathrm{BCMO2}$, cleave $\beta$-carotene & 11 & $\begin{array}{l}\text { rs11214139, rs2250417, } \\
\text { rs35361223 }\end{array}$ & 3 \\
\hline $\begin{array}{l}\text { Betaine-homocysteine S-methyl } \\
\text { transferase }\end{array}$ & BHMT, methylate Hcy & 5 & rs3733890 & 1 \\
\hline $\begin{array}{l}\text { Cholesteryl ester transfer protein, } \\
\text { plasma }\end{array}$ & CETP, transfer cholesterol & 16 & $\begin{array}{l}\text { rs12708980, rs5880, rs5882, } \\
\text { rs7205804, rs7499892 }\end{array}$ & 5 \\
\hline Cystathionine $\beta$-synthase & CBS, synthesize cystathionine & 21 & rs5742905 & 1 \\
\hline $\begin{array}{l}\text { Cytochrome P450, family 4, subfamily } \\
\text { F, polypeptide } 2\end{array}$ & CYP4F2, involved in cholesterol synthesis & 19 & $\begin{array}{l}\text { rs3093156, rs2108622, } \\
\text { rs3093168, rs3093194 }\end{array}$ & 4 \\
\hline $\begin{array}{l}\text { Folate hydrolate } \\
\text { (prostate specific membrane antigen) } 1\end{array}$ & FOLH1 (GCPII), hydrolyze folate & 11 & rs61886492 & 1 \\
\hline Methionine synthase reductase & MTRR, remethylate Hcy & 5 & rs1801394 & 1 \\
\hline Methylenetetrahydro-folate reductase & MTHFR, distribute one carbon units & 1 & rs1801131, rs1801133 & 2 \\
\hline $\begin{array}{l}\text { 5-Methyltetra-hydrofolate- } \\
\text { homocysteine methyltransferase }\end{array}$ & MTR, remethylate Hcy & 1 & rs1805087 & 1 \\
\hline $\begin{array}{l}\text { Microsomal triglyceride transfer } \\
\text { protein }\end{array}$ & MTTP, lipoprotein assembly & 4 & $\begin{array}{l}\text { rs10516445, rs1057613, } \\
\text { rs3828542, rs881980 }\end{array}$ & 4 \\
\hline $\begin{array}{l}\text { Niemann-Pick disease, type } \mathrm{C} 1 \text {, } \\
\text { gene-like } 1\end{array}$ & $\begin{array}{l}\text { NPC1L1, absorption of intestinal cholesterol } \\
\text { and a-tocopherol transport }\end{array}$ & 7 & $\begin{array}{l}\text { rs11763759, rs217420, } \\
\text { rs217430, rs217432 }\end{array}$ & 4 \\
\hline Retinol binding protein 1, cellular & CRBP2 (RBP2), & 3 & $\begin{array}{l}\text { rs2118981, rs35674260, } \\
\text { rs3772875 }\end{array}$ & 3 \\
\hline Scavenger receptor class B, member 1 & SCARB1, intestinal absorption of carotenoids & 12 & $\begin{array}{l}\text { rs } 10773105, \text { rs } 12582221 \\
\text { rs } 7306660, \text { rs } 7967521, \text { rs } 838892\end{array}$ & 5 \\
\hline $\begin{array}{l}\text { Serine palmitoyltransferase, long chain } \\
\text { base subunit } 1\end{array}$ & SPTLC1, sphingolipid biosynthesis & 9 & $\begin{array}{l}\text { rs11790991, rs2297568, } \\
\text { rs7858659 }\end{array}$ & 3 \\
\hline $\begin{array}{l}\text { Solute carrier family } 19 \\
\text { (folate transporter), member } 1\end{array}$ & SLC19A1, reduced folate carrier & 21 & $\begin{array}{l}\text { rs13050920, rs3788205, } \\
\text { rs3788199 }\end{array}$ & 3 \\
\hline $\begin{array}{l}\text { Solute carrier family } 46 \\
\text { (folate transporter), member } 1\end{array}$ & SLC46A1, proton coupled folate transporter (PCFT) & 17 & $\begin{array}{l}\text { rs11080058, rs1128162, } \\
\text { rs17719944, rs35714695, } \\
\text { rs739439 }\end{array}$ & 5 \\
\hline CD36 Thrombospondin receptor & $\begin{array}{l}\text { CD36, platelet surface glycoprotein, binds to } \\
\text { oxidized LDL }\end{array}$ & 7 & $\begin{array}{l}\text { rs1358337, rs3211834, } \\
\text { rs3211931, rs3211956 }\end{array}$ & 4 \\
\hline a-Tocopherol transfer protein & a-TTP, transport a-tocopherol & 8 & rs4501570, rs4587328, rs4606052 & 3 \\
\hline Transcobalamin II & TCII, transport vitamin B12 & 22 & rs1801198 & 1 \\
\hline \multicolumn{4}{|l|}{ Total SNP included in analysis } & 65 \\
\hline
\end{tabular}

Information regarding the 65 SNP included in the analysis. In the last column, $n$ denotes the number of SNP per gene.

blood samples has been previously described [2]. The results of RBC folate concentrations and plasma vitamin B12 levels are included in the online Supporting Information (Additional file 1: Figures S2 and S3). Briefly and specifically to this study, the lipid panel was completed using the Beckman LXI and LX20 Pro (Beckman Instruments, Brea, CA) at the Department of Pathology labo- ratory of the University of California, Davis. Results of serum triglycerides, total cholesterol, HDL-C, and LDL$\mathrm{C}$ are provided in the online Supporting Information (Additional file 1: Figures S4 S5, S6, S7). Additionally, genomic DNA was extracted from whole blood with the use of a PAXgene Blood DNA kit (PreAnalytix; Qiagen, Inc., Valencia, CA). 


\section{Beltsville population}

Blood was collected into serum separator tubes after a $12 \mathrm{~h}$ fast. Blood samples were allowed to sit for $30 \mathrm{~min}$ before centrifugation at $2000 \times g$ for $10 \mathrm{~min}$ at $4^{\circ} \mathrm{C}$ then aliquotted and stored at $-80^{\circ} \mathrm{C}$ until analysis. Plasmadeplete samples were analysed for folate concentration as described previously [2]. The results of $\mathrm{RBC}$ folate concentrations and plasma vitamin B12 levels are included in the online Supporting Information (Additional file 1: Figures S2 and S3). Thawed samples were analyzed in duplicate for HDL cholesterol on a Dade Behring Dimension xPand clinical chemistry analyzer (Siemens, Erlangen, Germany). Results of serum triglycerides, total cholesterol, HDL-C, and LDL-C are provided in the online Supporting Information (Additional file 1: Figures S4, S5, S6, S7). High quality DNA was extracted from white blood cells using the Gentra PureGene Blood DNA Purification Kit (Qiagen, Inc.) as was previously described [2] prior to SNP analysis.

\section{Genotyping of SNP}

Extracted DNA from both the Sacramento and Beltsville populations was analyzed using an allele discrimination assay with a MALDI-TOF mass spectrometry platform (Sequenom MassARRAY ${ }^{\circledR}$ ) (Neogen/GeneSeek Inc., Lincoln, NE). A total of 65 SNP in 23 genes were analysed. Candidate gene selection was performed based upon a literature search of pathways involving folate, lipids, vitamins A, E, and B12 metabolism. Specific SNP in relevant genes were obtained from dbSNP [53] and Ensembl [54] databases (Table 3).

\section{Data processing and statistical analysis Association analysis}

Marker-trait association analysis was performed using a linear regression test under an additive model assumption in Caucasian participants from both study populations only. The adjusted phenotype, $y$, was HDL levels adjusted for gender and body weight only (see discussion in Statistical significance of fixed effects, below). Statistical analyses were performed using the genotype association and regression modules from the SNP Variation Suite (SVS) version 7 (Golden Helix Inc., Bozeman, MT). In brief, the adjusted phenotype, $y$, was fit to every encoded genotype under an additive model assumption, $x$, and was represented with the following equation (1):

$$
y=b_{1} x+b_{0}+\varepsilon
$$

Where $y$ was the adjusted phenotype (HDL adjusted for gender and weight), $b_{1} x+b_{0}$ represented the model, and the error term, $\varepsilon$, expressed the random residual effect.

\section{Statistical significance of fixed effects}

Participant data (gender, age, height, weight, and calculated BMI) were tested to adjust phenotypes for systematic effects using a full (including covariates) versus reduced model regression equation. The regression sums of squares were calculated both for a reduced and for the full model. An F test was then performed to find the significance of the full versus the reduced model. A P-value threshold of 0.01 was used to establish significant associations. Gender and body weight effects were statistically significant; therefore, adjusted phenotypes were obtained for all samples.

The linear regression was also performed including SNP interactions using the SVS version 7 regression module from Golden Helix. FDR was controlled according to a previous method [55] and a cutoff for a significant association value was set at FDR q value $<0.01$.

\section{Additional file}

Additional file 1: Figure S1. Diet Folate Equivalent (DFE) histogram of Sacramento $(n=248)$ and Beltsville $(n=505)$ study participants. Figure S2: Red Blood Cell (RBC) folate concentrations histogram of Sacramento ( $n=248)$ and Beltsville $(n=509)$ study participants. Figure S3: Comparison of plasma vitamin B12 concentrations $(\mathrm{pg} / \mathrm{mL})$ in the Sacramento and Beltsville populations. Figure S4: Comparison of serum triglyceride levels in the Sacramento $(n=248)$ and Beltsville $(n=505)$ study participants. Figure S5: Comparison of total cholesterol $(\mathrm{mg} / \mathrm{dL})$ in the two study populations. Figure S6: Comparison of HDL cholesterol $(\mathrm{mg} / \mathrm{dL})$ in the two study populations. Figure S7: Comparison of LDL cholesterol $(\mathrm{mg} / \mathrm{dL})$ in the two study populations.

\section{Abbreviations}

SNP: Single nucleotide polymorphism(s); HDL and HDL-C: High-density lipoprotein high-density lipoprotein cholesterol; CETP: Gene symbol for cholesteryl ester transfer protein; SLC46A1: Gene symbol for solute carrier family 46 (folate transporter), member 1 or proton-coupled folate transporter; SLC19A1: Gene symbol for solute carrier family 19 (folate transporter), member 1, or reduced folate carrier; CD36: Gene symbol for thrombosponding receptor or glycoprotein IIIb/platelet glycoprotein IV; BCMO1: Gene symbol for beta-carotene monooxygenase 1; APOA5: Gene symbol for apolipoproteinA-V; ABCA1: Gene symbol for ATP-binding cassette transporter member 1; PPAR: Peroxisome proliferator-activated receptor; DM: Diabetes mellitus; CVD: Cardiovascular disease; SPTLC1: Gene symbol for serine palmitoyltransferase; SCARB1: Gene symbol for scavenger receptor class B type 1; CRBP2: Gene symbol for cellular retinol binding protein; BHMT: Gene symbol for betaine-homocysteine methyltransferase; MTHFR: Gene symbol for methylene tetrahydrofolate reductase; Hcy: Homocysteine; CHD: Coronary heart disease; LDL and LDL-C: Lowdensity lipoprotein and low-density lipoprotein cholesterol; RCT: Reverse cholesterol transport; ASE: Allele substitution effect; FDR: False discovery rate; MAF: Minor allele frequency; VLDL: Very low-density lipoproteins; CETP: Cholesteryl ester transfer protein; GWAS: Genome-wide association study; apolA1: Apolipoproteina-1; PCFT: Proton-coupled folate transporter; RFC: Reduced folate carrier; COMT: Catechol O-methyltransferase; CD36: Thrombosponding receptor or glycoprotein IIlb/platelet glycoprotein IV; BMI: Body mass index; BCMO1: Beta-carotene monooxygenase 1 ; NHANES: National Health and Nutrition Examination Survey;

APOA5: Apolipoproteina-V; ABCA1: ATP-binding cassette transporter member 1; ABCG1: ATP-binding cassette transporter G1; LPL: Gene symbol for lipoprotein lipase; apoE: Apolipoprotein E; $\mathrm{K}_{2}$ EDTA: Potassium ethylenediaminetetraacetic acid; RBC: Red blood cell; MALDI-TOF: Matrix-assisted laser desorption ionization time-of-flight; DFE: Dietary Folate Equivalents. 


\section{Competing interests}

The authors declare that they have no competing interests.

\section{Authors' contributions}

GR, JFM, and AJC designed the research; GR and JEO conducted the research; AJM, DJB, and JAN provided essential materials and data; GR performed statistical analyses and wrote the statistical methods section; JEO, GR, and AJC wrote the manuscript; DJB and JAN participated in manuscript preparation; and AJC had final responsibility for the content. All authors read and approved the final manuscript.

\section{Acknowledgements}

We are grateful to Alma Islas-Trejo for her work on the genotyping of the BHMT polymorphism. We thank the reviewers for their careful consideration of the manuscript and their helpful and perceptive comments.

This work was supported by grant no. DK 45939 from the National Institutes of Health, Grant/Cooperative Agreement no. RO1 8928 from the Centers for Disease Control and Prevention, and Regional Research Grant no. W2002, Project \#CA-D*-NTR-7778-H from the US Department of Agriculture. The contents are the sole responsibility of the authors and do not necessarily represent the official views of the $\mathrm{NIH}, \mathrm{CDC}$, or USDA.

\section{Author details}

'Department of Nutrition, University of California, One Shields Avenue, Davis, CA 95616, USA. ${ }^{2}$ Department of Animal Science, University of California, One Shields Avenue, Davis, CA 95616, USA. ${ }^{3}$ Department of Chemistry and Biochemistry, University of Colorado Colorado Springs, 1420 Austin Bluffs Parkway, Colorado Springs, CO 80918, USA. ${ }^{4}$ Food Surveys Research Group, US Department of Agriculture, Beltsville, MD 20705, USA. ${ }^{5}$ US Department of Agriculture, Food Components and Health Laboratory, Beltsville, MD 20705, USA

Received: 13 February 2013 Accepted: 2 May 2013

Published: 8 May 2013

\section{References}

1. Patel CJ, Cullen MR, loannidis JP, Butte AJ: Systematic evaluation of environmental factors: persistent pollutants and nutrients correlated with serum lipid levels. Int J Epidemiol 2012, 41:828-843.

2. Clifford AJ, Chen K, McWade L, Rincon G, Kim S-H, Holstege DM, Owens JE, Liu B, Muller H-G, Medrano JF, et al: Gender and single nucleotide polymorphisms in MTHFR, BHMT, SPTLC1, CRBP2, CETP, and SCARB1 are significant predictors of plasma homocysteine normalized by RBC folate in healthy adults. J Nutr 2012, 142:1764-1771.

3. Semmler A, Farmand S, Moskau S, Stoffel-Wagner B, Linnebank M: The G allele of transcobalamin $2 \mathrm{c.776C} \rightarrow \mathrm{G}$ is associated with an unfavorable lipoprotein profile. Ann Nutr Metab 2010, 57:112-115.

4. Kitami T, Rubio R, O'Brien W, Quackenbush J, Nadeau JH: Geneenvironmental interactions reveal a homeostatic role for cholesterol metabolism during dietary folate perturbation in mice. Physiol Genomics 2008, 35:182-190.

5. Corsetti JP, Ryan D, Moss AJ, McCarthy J, Goldenberg I, Zareba W, Sparks CE: CD3, CD36 Thrombospondin-4 polymorphism (A387P) predicts cardiovascular risk in postinfarction patients with high HDL cholesterol and C-reactive protein levels. Thromb Haemost 2011, 106:993-1234

6. Kim DS, Burt AA, Ranchalis JE, Richter RJ, Marshall JK, Nakayama KS, Jarvik ER, Eintracht JF, Rosenthal EA, Furlong CE, Jarvik GP: Dietary cholesterol increases paraoxonase 1 enzyme activity. J Lipid Res 2012, 53:2450-2458.

7. Zelijkovic A, Vekic J, Spasojevic-Kalimanovska V, Jelic-Ivanovic Z, Peco-Antic A, Kostic M, Vasic D, Spasic S: Characteristics of LDL- \& HDL-subclasses in pediatric renal transplant patients. Transpl Int 2011, 24:1094-1102.

8. Hewing B, Fisher EA: Rationale for cholesteryl ester transfer protein inhibition. Curr Opin Lipidol 2012, 23:372-376.

9. Gauthier A, Lau P, Zha X, Milne R, McPherson R: Cholesteryl ester transfer protein directly mediates selective uptake of high density lipoprotein cholesteryl esters by the liver. Arterioscler Thromb Vasc Biol 2005, 25:2177-2184.

10. Davidson MH: HDL and CETP Inhibition: Will this DEFINE the Future? Curr Treatm Options Cardiovasc Med 2012, 14:384-390.

11. Zhang L, Yan F, Zhang S, Lei D, Charles MA, Cavigiolio G, Oda M, Krauss RM, Weisgraber $\mathrm{KH}$, Rye KA, et al: Structural basis of transfer between lipoproteins by cholesteryl ester transfer protein. Nat Chem Biol 2012, 8:342-349.
12. Drenos TF, Talmud PJ, Casas JP, Smeeth L, Palmen J, Humphries SE, Hingorani AD: Integrated associations of genotypes with multiple blood biomarkers linked to coronary heart disease risk. Hum Mol Genet 2009, 18:2305-2316.

13. Pan SL, Wang F, Lu ZP, Liu CW, Hu CY, Luo H, Peng JH, Luo XQ, Pang GF, Lu $\mathrm{SH}$, et al: Cholesteryl ester transfer protein TaqIB polymorphism and its association with serum lipid levels and longevity in Chinese Bama Zhuang population. Lipids Health Dis 2012, 11. doi:10.1186/1476-511X-11-26.

14. Teslovich TM, Musunuru K, Smith AV, Edmondson AC, Stylianou IM, Koseki M, Pirruccello JP, Ripatti S, Chasman DI, Willer CJ, et al: Biological, clinical, and population relevance of 95 loci for blood lipids. Nature 2010, 466:707-713.

15. Tietjen I, Hovingh GK, Singaraja RR, Radomski C, Barhdadi A, McEwen J, Chan E, Mattice M, Legendre A, Franchini PL, et al: Segregation of LIPG, CETP, and GALNT2 mutations in Caucausian familesi with extremely high HDL cholesterol. PLoS One 2012, 7:e37437.

16. Thompson A, Angelantonio ED, Sarwar N, Erquo S, Saleheen D, Dullart RPF Keavney B, Ye Z, Danesh J: Association of cholesteryl ester transfer protein genotypes with CETP mass and activity, lipid levels, and coronary risk. J Amer Med Assoc 2008, 299:2777-2788.

17. Rejeb J, Omezzine A, Boumaiza I, Rebhi L, Rejeb NB, Nabli N, Abdelaziz AB, Boughzala E, Bouslama A: Four polymorphisms of cholesteryl ester transfer protein gene and coronary stenosis in a Tunisian population. J Cardiovasc Med (Hagerstown) 2012, 13:546-553.

18. Desmoulin SK, Hou Z, Gangjee A, Matherly LH: The human proton-coupled folate transporter: Biology and therapeutic applications to cancer. Cancer Biol Ther 2012, 13:1-19.

19. Semmler A, Moskau S, Grigull A, Farmand S, Klockgether T, Smulders YM, Blom HJ, Zur B, Stoffel-Wagner B, Linnebank M: Plasma folate levels are associated with the lipoprotein profile: a retrospective database analysis. Nutr J 2010, 9:31-34.

20. Mauritz R, Peters GJ, Kathmann I, Teshale H, Noordhuis P, Comijn EM, Pinedo HM, Jansen G: Dynamics of antifolate transport via the reduced folate carrier and the membrane folate receptor in murine leukaemia cells in vitor and in vivo. Cancer Chemother Pharmacol 2008, 62:937-948.

21. Mahabir S, Ettinger S, Johnson L, Baer DJ, Clevidence BA, Hartman TJ, Taylor PR: Measures of adiposity and body fat distribution in relation to serum folate levels in postmenopausal women in a feeding study. Eur J Clin Nutr 2008, 62:644-650

22. Carter MF, Powell TL, Li C, Myatt L, Dudley D, Nathanielsz P, Jansson T: Fetal serum folate concentrations and placental folate transport in obese women. Am J Obstet Gynecol 2011, 205:83.e17-83.e25.

23. Rac ME, Suchy J, Kurzawski G, Kurlapska A, Safranow K, Rac M, Sagasz-Tysiewicz D, Krzystolik A, Poncyljusz W, Jakubowska K, et al: Polymorphism of the CD36 gene and cardiovascular risk factors in patients with coronary artery disease manifested at a young age. Biochem Genet 2012, 50:103-111.

24. Knowles JW, Wang $H$, Itakura $H$, Southwick A, Myers RM, Iribarren C, Fortmann SP, Go AS, Quertermous T, Hlatky MA: Association of polymorphisms in platelet and hemostasis system genes with acute myocardial infarction. Am Heart J 2007, 154:1052-1058.

25. Heni M, Mussing K, Machicao F, Machann J, Schick F, Claussen CD, Stefan N, Fritsche A, Haring $\mathrm{HU}$, Staiger $\mathrm{H}$ : Variants in the CD36 gene locus determine whole-body adiposity, but have no independent effect on insulin sensitivity. Obesity 2011, 19:1004-1009.

26. Chien KL, Hsu HC, Liu PH, Lin HJ, Chen MF: Common sequence variants in CD36 gene and the levels of triglyceride and high-density lipoprotein cholesterol among ethnic Chinese in Taiwan. Lipids Health Dis 2012, 11 doi:10.1186/1476-511X-11-174.

27. Ferrucci L, Perry JR, Matteini A, Perola M, Tanaka T, Silander K, Rice N, Melzer $D$, Murray A, Cluett $C$, et al: Common variation in the beta-carotene 15,15'-monooxygenase 1 gene affects circulating levels of carotenoids: a genome-wide association study. Am J Hum Genet 2009, 84:123-133.

28. Wang CX, Wongsiriroj N, Deckelbaum RJ, Blaner WS, Harrison EH: New findings on apo-carotenoid metabolites of B-carotene. Sight and Life 2012, 26:18-27.

29. Lietz G, Oxley A, Leung W, Hesketh J. Single nucleotide polymorphism upstream from the B-carotene 15,15'-monoxygenase gene influence provitamin A conversion efficiency in female volunteers. J Nutr 2012 , 142:161S-165S.

30. Eroglu A: Hruszkewycz DP, dela Sena C, Narayanasamy S, Riedl KM Kopec RE, Schwartz SJ, Curley RWJ, Harrison EH: Naturally occuring eccentric cleavage products of provitamin A B-carotene function as antagonists of retinoic acid receptors. J Biol Chem 2012, 287:15886-15895. 
31. Harrison EH: dela Sena C, Eroglu A, Fleshman MK: The formation, occurrence, and function of B-apocarotenoids: B-carotene metabolites that may modulate nuclear receptor signaling. Am J Clin Nutr 2012, 96:1189S-1192S.

32. Perry JR, Ferrucci L, Bandinelli S, Guralnik J, Semba RD, Rice N, Melzer D, Saxena R, Scott LJ, McCarthy Ml, et al: Circulating beta-carotene levels and type 2 diabetes - cause or effect? Diabetologia 2009, 52:2117-2121.

33. Liu ZK, Hu M, Baum L, Thomas GN, Tomlinson B: Associations of polymorphisms in the apolipoprotein A1/C3/A4/A5 gene cluster with familial combined hyperlipidaemia in Hong Kong Chinese. Atherosclerosis 2010, 208:427-432

34. Yin RX, Li Y-Y, Lai C-Q: Apolipoprotein A1/C3/A5 haplotypes and serum lipid levels. Lipids Health Dis 2011, 10:1-16.

35. Li Y-Y, Yin RX, Lai C-Q, Li M, Long X-J, Li K-L, Liu W-Y, Zhang L, Wu J-Z Association of apolipoprotein A5 gene polymorphisms and serum lipid levels. Nutr Metab Cardivasc Dis 2011, 21:947-956.

36. Vedhachalam C, Duong PT, Nickel M, Nguyen D, Dhanasekaran P, Saito H, Rothblat GH, Lund-Katz S, Phillips MC: Mechanism of ATP-binding cassette transporter A1-mediated cellular lipid efflux to apolipoprotein A-1 and formation of high density lipoprotein particles. J Biol Chem 2007, 282:25123-25130.

37. Denis M, Landry YD, Zha X: ATP-binding cassette A1-mediated lipidation of apolipoprotein A-1 occurs at the plasma membrane and not in the endocytic compartments. J Biol Chem 2008, 283:16178-16186.

38. Kolsch H, Lutjohann D, Jessen F, Von Bergmann K, Schmitz S, Urbach H, Maier W, Heun R: Polymorphism in ABCA1 influences CSF 24Shydroxycholesterol levels but is not a major risk factor of Alzheimer's disease. Int J Mol Med 2006, 17:791-794.

39. Sorci-Thomas MG, Owen JS, Fulp B, Bhat S, Zhu X, Parks JS, Shah D, Jerome WG, Gerelus M, Zabalawi M, Thomas MJ: Nascent high density lipoproteins formed by $A B C A 1$ resemble lipid rafts and are structurally organized by three apoA-1 monomers. J Lipid Res 2012, 53:1890-1909.

40. Kennedy MA, Barrera GC, Nakamura K, Baldan A, Tarr P, Fishbein MC, Frank J, Francone OL, Edwards PA: ABCG1 has a critical role in mediating cholesterol efflux to HDL and preventing cellular lipid accumulation. Cell Metab 2005, 1:121-131.

41. Linga Reddy MV, latan I, Weissglas-Volkov D, Nikkola E, Haas BE, Juvonen M, Ruel I, Sinsheimer JS, Genest J, Pajukanta P: Exome sequencing identifies two rare variants for low HDL-C in an extended family. Circ CardiovasC Genet 2012, 5:538-546.

42. Ayaori M, Yakushjii E, Ogura M, Nakaya K, Hisada T, Uto-Kondo H, Takiguchi S, Terao Y, Sasaki M, Komatsu T, et al: Retinoic acid receptor agonists regulate expression of ATP-binding cassette transporter G1 in macrophages. Biochim Biophys Acta 1821, 2012:561-572.

43. Wiersma H, Nijstad N, de Boer JF, Out R, Hogewerf W, van Berkel TJ, Kuipers F, Tietge UJ: Lack of Abcg1 results in decreased plasma HDL cholesterol levels and increased biliary cholesterol secretion in mice fed a high cholesterol diet. Atherosclerosis 2009, 206:141-147.

44. Bodzioch M, Orso E, Klucken J, Langmann T, Bottcher A, Diederich W, Drobnik W, Barlage S, Buchler C, Porsch-Ozcurumez M, et al: The gene encoding ATP-binding cassette transporter 1 is mutated in Tangier disease. Nat Genet 1999, 22:347-351.

45. Brooks-Wilson A, Marcil M, Clee SM, Zhang L-H, Roomp K, van Dam M, Brewer C, Collins JA, Molhuizen HOF, Loubser O, et al: Mutations in ABC1 in Tangier disease and familial high-density lipoprotein deficienc. Nat Genet 1999, 22:336-345.

46. Porchay I, Pean F, Bellili N, Royer B, Cogneau J, Chesnier M-C, Caradec A Tichet J, Balkau B, Marre M, Fumeron F: ABCA1 single nucleotide polymorphisms on high-density lipoprotein-cholesterol and overweight: the D.E.S.I.R. study. Obesity 2006, 14:1874-1879.

47. Soro-Paavonen A, Naukkarinen J, Lee-Rueckert M, Watanabe H, Rantala E, Soderlund S, Hiukka A, Kovanen PT, Jauhianen M, Peltonen L, Taskinen M-R: Common $A B C A 1$ variants, HDL levels, and cellular cholesterol efflux in subjects with familial low HDL. J Lipid Res 2007, 48:1409-1416.

48. Wang J, Burnett JR, Near S, Young K, Zinman B, Hanley AJG, Connelly PW, Harris SB, Hegele RA: Common and rare $A B C A 1$ variants affecting plasma HDL cholesterol. Arterioscler Thromb Vasc Biol 2000, 20:1983-1989.

49. Voight BF, Peloso GM, Orho-Melander M, Frikke-Schmidt R, Barbalic M, Jensen MK, Hindy G, Hólm H, Ding EL, Johnson T, et al: Plasma HDL cholesterol and risk of myocardial infarction: a mendelian randomisation study. Lancet 2012, 380:572-580. Erratum in: Lancet, 2012 Aug 2011;2380(9841):2564.
50. Annema W, Dikkers A: Freark de Boer J, Gautier T, Rensen PC, Rader DJ, Tietge UJ: ApoE promotes hepatic selective upatke but not RCT due to increased ABCA1-mediated cholesterol efflux to plasma. J Lipid Res 2012, 53:929-940.

51. Zhang LH, Kamanna VS, Ganji SH, Xiong XM, Kashyap ML: Niacin increases $\mathrm{HDL}$ biogenesis by enhancing DR4-dependent transcription of ABCA and lipidation of apolipoprotein A-1 in HepG2 cells. J Lipid Res 2012 53:941-950

52. Moshfegh AJ, Rhodes DG, Baer DJ, Murayi T, Clemens JC, Rumpler W, Paul DR, Sebastian RS, Kuczynksi KJ, Ingwersen LA, et al: The US Department of Agricultur Automated Multiple-Pass Method reduces bias in the collection of energy intakes. Am J Clin Nutr 2008, 88:324-332.

53. dbSNP Home Page: Short Genetic Variations. http://www.ncbi.nlm.nih.gov/ projects/SNP/; Last accessed 06/21/2012

54. e!Ensembl. http://uswest.ensembl.org/index.html; Last accessed 06/21/2012

55. Storey J: A direct approach to false discovery rates. J R Statist Soc 2002, B 64:479-498.

doi:10.1186/1476-511X-12-66

Cite this article as: Clifford et al:: Single nucleotide polymorphisms in CETP, SLC46A1, SLC19A1, CD36, BCMO1, APOA5, and ABCA1 are significant predictors of plasma $\mathrm{HDL}$ in healthy adults. Lipids in Health and Disease 2013 12:66

\section{Submit your next manuscript to BioMed Central and take full advantage of:}

- Convenient online submission

- Thorough peer review

- No space constraints or color figure charges

- Immediate publication on acceptance

- Inclusion in PubMed, CAS, Scopus and Google Scholar

- Research which is freely available for redistribution

Submit your manuscript at www.biomedcentral.com/submit
C Biomed Central 